\title{
Memantine in neurological disorders - schizophrenia and depression
}

\author{
Kamila Czarnecka ${ }^{1}$ (iD) · Jakub Chuchmacz ${ }^{1} \cdot$ Przemysław Wójtowicz ${ }^{1} \cdot$ Paweł Szymański $^{1}$ (i)
}

Received: 1 March 2020 / Revised: 22 June 2020 / Accepted: 18 September 2020 / Published online: 14 January 2021

(C) The Author(s) 2021

\begin{abstract}
Memantine is used in Alzheimer's disease treatment as a non-competitive modern-affinity strong voltage-dependent N-methyl$\mathrm{D}$-aspartate receptor antagonist. The fundamental role of these receptors is to bind glutamate: the main excitatory neurotransmitter in the brain, believed to play a crucial role in neuronal plasticity and learning mechanisms. Glutamate transmission plays an important role in all internal CNS structures and maintains the physiological state of the brain. Excessive glutamate transmission can lead to enlarged calcium ion current which may cause neurotoxicity; however, insufficient transmission can drastically alter the information flow in neurons and the brain, potentially causing schizophrenia-like symptoms by replacing lost information with completely new stimuli. Hence, it is possible that the modulation of NMDA activity may give rise to pathophysiological states. Available literature and clinical trials indicate that memantine is well tolerated by patients, with very few and light side effects. There is a belief that memantine may also benefit other conditions such as schizophrenia and depression.
\end{abstract}

Keywords Memantine $\cdot$ Alzheimer's disease $\cdot$ Schizophrenia $\cdot$ Depression

\section{Introduction}

Memantine is used for treating patients with Alzheimer's disease (AD), with various degrees of severity. This common neurodegenerative disorder, characterized by progressive loss of memory and cognitive function, is currently incurable and affects around 15 million people worldwide [1]. Initial symptoms usually appear after the age of 65 and become more severe with age, with the prevalence increasing from $0.5 \%$ at age 65 to as high as $8 \%$ by 85 . AD currently accounts for around $50-75 \%$ of dementia cases [2]. Dementia itself has been known by humans for centuries and it is major cause of dependence, mortality, and disability [3]. Currently, over 44 million people worldwide are affected by dementia, and this number is expected to triple by the year 2050 [2, 3]. In 2015, dementia contributed to $11.6 \%$ of all deaths in England and Wales and the number of people suffering from dementia is still rising [4-7].

Kamila Czarnecka

kamila.czarnecka@umed.lodz.pl

Paweł Szymański

pawel.szymanski@umed.lodz.pl

1 Department of Pharmaceutical Chemistry, Drug Analyses and Radiopharmacy, Faculty of Pharmacy, Medical University of Lodz, Muszynskiego 1, 90-151 Lodz, Poland
Effective treatment is complicated by a rage of sociological issues, such as low community awareness [8], and the lack of valid epidemiological data. However, we can say that every generation is different: both their level of education and, unfortunately, interest in health vary considerably. In addition, levels of medical care and established medical factors such as cardiovascular risk, diabetes, or metabolic syndrome differ between nations, and human life span is continually extending $[7,9]$. Recent reports indicate that age-related symptoms of dementia will significantly decrease in people born in the second part of the twentieth century [10]; these may provide a better understanding of potentially modifiable factors of dementia $[10,11]$. Significant roles are also played by the socioeconomic status of the patient and the local community: communities in less developed countries are more likely to experience non-communicable diseases (NCDs), and are more exposed to their causative factors, such as smoking, alcohol intake, and health policies [11].

The literature includes no records of dementia until 1907, when Alois Alzheimer reported the case of a woman who experienced memory loss, believed to have arisen as a consequence of her jealousy toward her husband; she also demonstrated abnormal behavior, such as collecting and misplacing items and a belief that someone was spying on her and was trying to kill her [12]. After her death, autopsy indicated the presence of neurofibrillary tangles and senile plaques in the 
neocortex and hippocampus [12]. These signs are now known as B-amyloid peptide plaques, comprising elements of degenerated neurons, lost neurons, and synapses, and tangles composed of improperly phosphorylated tau-protein [13]. Their presence is believed to reflect the initial pathogenesis of $\mathrm{AD}$. According to the amyloid hypothesis [3], AD progresses together with the accumulation of a pathological peptide (B-amyloid) in the brain induced by a physiological imbalance between the production and elimination of B-amyloid by B- and Y-secretases; this accumulation is followed by the development of neuropil threads, dystrophic neurites, associated astrogliosis, and microglial activation. The formation of these pathological plaques and the subsequent inflammationmediated neurodegeneration are thought to inhibit neurotransmission [11].

However, the pathogenesis of AD is also influenced by genetic factors, and they are thought to trigger around $70 \%$ of all cases [3,13]. Autosomal dominant disorders could also trigger some cases of $\mathrm{AD}$, and the gene which produces amyloid precursor protein (APP) or the presenilins (PS1 or PS2) also produce a protein which harms vulnerable neurons, causing progressive dementia [14]. The APOE gene (apolipoprotein E) can occur in four variants: E1, E2, E3, and E4. The expression of the $\mathrm{E} 4$ form can increase the chance of promoting $\mathrm{AD}$ fourfold, with the odds ratio rising from 3 to 12 [15]. Under physiological conditions, APOE gene plays a fundamental role in cholesterol synthesis. In addition, the pathogenesis of $\mathrm{AD}$ has been associated with more than 20 different genes that play roles in the inflammatory process, endosomal vesicle recycling, and cholesterol metabolism [16].

Memantine was first approved by the FDA on 16 October 2003 and on 17 May 2002 in the European Union. It was first synthesized in Germany by Elly Lilly in 1968 as a potential antidiabetic drug; however, it was found to not be capable of lowering blood sugar level [17]. It was later discovered to have a potential influence on CNS activity, and was entered into clinical trials in 1986. Three years later, in 1989, it was confirmed to demonstrate uncompetitive blocking of NMDA receptors (N-methyl-D-aspartate) $[16,18,19]$. This receptor is one of the three classes of receptors (AMPA, Kainate, NMDA) which bind glutamate: a very important factor for physiological CNS functioning and one that acts as the main excitatory neurotransmitter in the mammalian brain. However, neurotransmitter activation is complex and requires the presence of both glycine and glutamate: the former remains at a constant level in the extracellular fluid, where it serves as a modulator, while glutamate is released from presynaptic stores in a constant manner, thus playing the role of neurotransmitter. Both are required to open integrated voltage-dependent calcium ion channels. Such depolarization removes the channel blockade provided by magnesium ions, which links the NMDA receptors to the electrical activity of the neuron and enables to connect neurotransmitter reproach to electrical state of neuron [20]. When NMDA transmission is sustained, it promotes various neuronal mechanisms, such as gene activation, and enhances learning and memory by ensuring synaptic plasticity. However, excess NMDA activation results in an increase in the levels of calcium ions, resulting in excitotoxicity [20,21].

Memantine was initially believed to offer great promise: despite blocking NMDA, its administration did not entail specific NMDA antagonist side effects. This property has been attributed to the strong voltage dependency of this ligand [21]. Memantine is an uncompetitive weak antagonist of the NMDA receptor. It is bound to a slightly different region of the ion channel than magnesium ions, and with a slightly stronger bond [20, 21]. Despite this, the depolarization mechanism used to remove the blockade remains the same: the blockage becomes detached when depolarization is strong enough $[21,22]$. Although a number of existing drugs, such as dizocilpine, ketamine, and phencyclidine, also noncompetitively inhibit NMDA receptors, they have not been registered for such indications. The problem is its kinetics: it binds easily to the PCP (phencyclidine) part of the NMDA receptors, but the connection is so strong that it does not permit physiological inhibition of the receptor by magnesium ions when receiving an impulse. This can result in psychosis, delusions, anxiety, and mainly negative symptoms due to excessive glutaminergic transmission [21, 23, 24].

Excessive glutaminergic activity plays a significant role in the pathogenesis of neurodegenerative disorders [22], due to an overabundance of information reaching the brain. Such a glut of information complicates the segregation and selection of correct information [22], as well as promoting necrosis of brain cells and increasing the level of apoptosis. On the other hand, strong blockage of NMDA receptors prevents the passage of impulses, and this is believed to lead to hallucinations or psychosis by the blocked impulses being replaced with fragments of different ones [20].

Controlled clinical trials have found memantine to be the first drug to alleviate the symptoms of dementia and to significantly slow down neurodegenerative processes. In addition, a number of clinical trials, some of them unfinished, have examined the potential use of memantine in the treatment of other neurological diseases. Memantine has a wide potential range of uses as a neuroprotective agent, and this range could be extended further. Today, the most promising additional use of memantine is in schizophrenia and depression.

\section{Schizophrenia}

Schizophrenia is a psychotic disorder associated with damaged dopaminergic transmission in the brain [25]. It is characterized by a pathologically altered perception, unsettled connection with the external surroundings, and incorrect 
evaluation of external stimuli [25]. Psychotic patients demonstrate a significantly impaired ability to evaluate situations, state of mind, and thoughts, as well as social and family relationships [26]. Subjects can be unaware of the condition and may even refuse to accept it, which makes schizophrenia hard to treat. The condition impairs identity and most of the complex functions of human brain, resulting in great psychological and physical pain. Patients report that they feel they are "losing their mind" [25].

Although symptoms vary between patients, the core features are positive symptoms, such as delusions, hallucinations, and psychosis, which are attributable to excessive transmission in the mesolimbic dopamine system and negative symptoms, such as social withdrawal, and lack of spontaneous speech and motivation, that arise due to insufficient dopamine level in the mesocortical tract. Cognitive impairment is also present to greatly varying degrees. While the positive symptoms tend to arise temporarily as psychotic periods, the negative symptoms are more constant and chronic [27].

In many cases, this disease never resolves; however, a number of antipsychotic drugs have been discovered and they are helpful in alleviating the symptoms of schizophrenia and its commonly co-occurring conditions, such as depression, lack of motivation, or anxiety. The precise causes of schizophrenia remain unclear, but they are believed to be both environmental and genetic [25]. According to the neurodevelopmental hypothesis, the main paradigm for understanding environmental contributions, early neurodevelopment during pregnancy may play a key role in the development of the disease [28]. Factors such as maternal stress, infections, nutritional deficiencies during pregnancy, and birth or pregnancy complications may matter. In addition, the living environment of the growing child such as a city environment, socioeconomic factors, and the immigration of first and even second generation have also been associated with schizophrenia. Children born in late winter or early spring, or children with parents aged over 40 years or under 20 years, are also more likely to develop schizophrenia [28]. It is possible that these environmental agents can induce schizophrenia by affecting the expression of genes, but in this case the mechanism is more complex.

The first drugs developed to alleviate schizophreniaassociated symptoms are the neuroleptic or antipsychotic drugs such as chlorpromazine, thioridazine, or haloperidol. Those drugs differ slightly in terms of their activity or pharmacokinetics so they can be used in different kinds of schizophrenia or psychotic diseases. Nevertheless, they share a common mechanism of action. Neuroleptics act by inhibiting dopamine receptors, mainly D2 but also D1, D3, and D4, in accordance with the dopamine theory: the most commonly accepted theory in the epidemiology of schizophrenia [27]. However, these drugs also possess a number of side effects due to their inhibitory effects on other receptors, such as 5-
HT-2, H1 M1, or adrenergic receptors [24]. The main problem associated with their use in treating schizophrenic patients is that they inhibit dopaminergic transmission throughout the brain.

Dopamine has a strong influence on human behavior, and large-scale blockage of dopamine receptors results in the development of side effects; therefore, although inhibiting dopamine receptors in mesolimbic tract may alleviate positive symptoms, this approach may also increase the strength of negative symptoms. It has been very difficult to obtain a drug which can intensify transmission in one part of the brain and decrease it in another. Although more selective drugs, such as clozapine or olanzapine, have been found to significantly reduce extrapyramidal symptoms, both positive and negative symptoms are inhibited by their action [24, 26, 29]. Despite the popularity of the dopamine theory, it does not fully account for the appearance of schizophrenia symptoms during excessive or decreased glutaminergic transmission. Hence, it has been proposed that schizophrenia may be caused by improper glutaminergic transmission in parts of the brain connected with the disease; this is known as the glutaminergic hypothesis [21, 27, 29-31]. This hypothesis is supported by evidence derived from clinical patients with established psychosis or hallucinations, as well as negative and other symptoms of schizophrenia, who were administered strong NMDA antagonists such as ketamine or dizocilpine. In addition, the NMDA receptors and glutaminergic tracts playing a role in schizophrenia can also be influenced on the genetic level [21, 28]. Furthermore, subcutaneous injections of NMDA antagonists caused neurodegenerative changes in rat brain cortex, similar to those occurring in the schizophrenic brain $[21,32]$.

Hence, memantine, an NMDA blocker and a strongly voltage-dependent compound which does not impair the physiological role of NMDA receptors, has been examined as a potential treatment for schizophrenia. Studies show it may have potential in treating both positive and negative symptoms of schizophrenia [30]. When administered as an add-on to antipsychotics, memantine shows significant alleviation of positive and negative symptoms recorded using the PANSS (Positive and Negative Symptom Scale) or Calgary Depression Scale of Schizophrenia (CDSS) tools [30]. In addition, double-blinded controlled placebo trials have shown a significant reduction of positive symptoms in patients suffering from schizophrenia compared with placebo without any serious side effects. The changes observed in the psychiatric scales above were not influenced by environment or the length of the trial [2]; however, it is important to emphasize that memantine was not used as monotherapy in those studies, but as an adjuvant to traditional antipsychotic therapy [21, $30,32]$.

One study has shown that memantine may not only provide relief of the symptoms but could also modify the disease direction. Interestingly, significant differences between results 
have also been found between men and women [32]. These differences may come from physiological differences between males and females such as level of sex hormones, neurodevelopment, and also psychosocial factors. It is also claimed that females are more sensitive to neurotoxicity caused by glutamate [32]; however, it is important to emphasize that this trend is not shared by all antipsychotic drugs. It is worth adding that no significant difference in side effects was observed between memantine and placebo [31, 32], and that the side effects of memantine vary between people suffering from schizophrenia and those with Alzheimer's disease, which may be related to differences in the psychological state [32]. Any lack of differences may be caused by the relatively short duration of the trial [32].

Memantine treatment has been found to alleviate not only the positive symptoms of schizophrenia, but also the negative symptoms; this is a promising result because the negative symptoms are the main reason for withdrawal from society and the lack of motivation which worsens overall clinical state of the patient [29]. One studied case found that adding memantine to risperidone therapy significantly decreased the degree of negative symptoms [26]. One case study found a patient to report improvement after 6 weeks on a regimen of $10 \mathrm{mg} /$ day memantine. He was rated 96 on the SANS scale (Scale for the Assessment of Negative Symptoms), 3 in SAPS (Scale for the Assessment of Positive Symptoms), 3 in MMSE (Mini-Mental State Examination), and 2 in CDSS (Calgary Depression for Schizophrenia Scale). Following a dose increase to $20 \mathrm{mg}$ /day, the typical dose for Alzheimer's disease, he was rated SANS 76, SAPS 1, MMSE 26, and CDSS 1. Two months later, SANS had dropped to 70 and MMSE was 27, with SAPS and CDSS remaining the same [26]. No additional side effects were observed. The increased level of glutamate release in schizophrenia may be caused by NMDA receptor hypoactivity. For this reason, reversing this by NMDA receptor antagonist could represent a promising strategy to treating schizophrenia symptoms [33].

NMDA activity can also influence the course of schizophrenia by modulating the release of glutamate following the binding of serotonin or dopamine to $5 \mathrm{HT}_{2 \mathrm{a}}$ receptors $[29,34]$. Atypical antipsychotics such as risperidone, found to alleviate positive symptoms almost completely in one studied case, can reduce hyperactivity of glutamate by binding to 5 HT2a, and reduce dopamine release in the mesolimbic tract, and the combination of memantine and an atypical antipsychotic such as risperidone may prove an effective therapeutic option [29]. However, before any trial, it has been proposed that patients should be stabilized in terms of positive, extrapyramidal, and depression symptoms to ensure that any improvement can be attributed to pharmacotherapy [29].

Memantine also inhibits 5-HT-3 receptors, and it has been suggested that 5-HT-3 antagonists may improve negative symptoms $[19,34]$. It may have a positive effect on negative, positive, and psychopathology functions but it pries results of the other trials [19]. Memantine was also found to offer promise in the treatment of catatonic schizophrenia: a case study found a patient to demonstrate significant improvement after memantine treatment, speaking more slowly and developing independence in daily routines such as shaving or taking a shower. This condition improved further with the discontinuation of other CNS drugs such as fluoxetine or donepezil, and greater improvement was observed at higher doses of memantine. This state deteriorated rapidly following discontinuation, but improved again after dose restoration. After 40 days of recovery, the patient was able to answer questions immediately and easily during normal conversation. Although no additional side effects were observed in this case, studies have found that memantine use may be associated with adverse reactions such as psychosis and seizures [35].

MRI studies of patients with schizophrenia have found brain activity to increase after adding memantine to antipsychotic therapy [31]. In contrast, other studies have found the addition of memantine did not significantly increase all positive or depressive symptoms; however, in these cases, the drug was discontinued or produced side effects such as dizziness, headache, constipation, or nausea [36]. Adding memantine to therapy in a group of patients taking risperidone showed less heterogeneity in terms of negative symptoms than in patients on other antipsychotics; this observation confirms the results of earlier studies. It was also found that younger patients displayed greater alleviation of symptoms [37]. Elsewhere, no significant difference was found between patients with schizophrenia on combined atypical antipsychotic plus memantine therapy and placebo with regard to outcome, and although memantine increases cognitive functions in patients with dementia, it does not appear to improve cognitive functions in healthy patients [36]. Although the study population may have been irregular, this does not exclude that memantine may be helpful in treating patients with more severe psychopathological disorders. Population included in the study was considerably younger and severity of symptoms was average. The study included a wide range of antipsychotics, and little is known about the interactions between memantine and other antipsychotic drugs [36].

The findings obtained by clinical trials vary slightly. Some cases show significant improvement in clinical state, after various periods of time. It shows potency in memantine in treating schizophrenia. These differences may be attributable to the presence of excessive or insufficient glutaminergic transmission [31]. Unfortunately, our understanding of the epidemiology of schizophrenia remains incomplete as the disease may vary considerably between different patients and many different types exist. Hence, a range of antipsychotics or antidepressant drugs is required to maintain a stable psychological condition, and this variation can significantly affect the results of a trial. Nevertheless, larger blinded, controlled, 
randomized trials and more focused research on schizophrenia epidemiology are needed to provide more targeted trials [31].

\section{Depression}

Since the first published record of depressive disorders in psychiatric reviews in 1880, the prevalence of major depressive disorder has continued to grow [38].

A synthesized concept of mood disorders was published in 1899 by Kraepelin [39]. This was followed in 1934 by a manuscript describing depressive state as an unpleasant affect without organic changes in the brain or any schizophrenic disorder; these observations indicate that the affective changes appear primary, not secondary to other symptoms [40].

Depression affects $15-20 \%$ of the population and is a significant cause of morbidity worldwide due to suicide. It is associated with mood alteration, psychosocial impairment, and various neurochemical changes, and is always connected with diminished quality of life [38]. In some cases, it is also associated with cognitive impairment. Stress is also described as a factor which can affect the chance of developing depression $[41,42]$.

The treatment of major depressive disorder is quite complex because it is not a homogeneous state with different symptoms than may occur rarely; therefore, two opposite states can be the same symptom but it mainly concerns its intensity. Despite the heterogeneous character of the disease, some guidelines and schemes have been obtained to aid classification [43]. As each case is potentially unique, it is important to consider personal criteria such as tolerability when planning pharmacotherapy. Therapy should be adjusted to the type of the disorder and its dimension: for example, mood-sad, irritable, low, suicidal; activity or sleepinsomnia or hypersomnia [44].

Different types of depression exist, such as poststroke depression, postpartum depression, and posttraumatic depression, among others. [45-47]. The primary mechanism of depression is accounted for by the monoamine hypothesis, which claims that this state is the effect of insufficient level of noradrenaline and/or serotonin in the brain [48, 49]. Although today this theory is regarded as an oversimplification of depression, it nevertheless led to the discovery of drugs such as SSRI (selective serotonin reuptake inhibitors), SNRI (selective noradrenaline reuptake inhibitors), or monoamine oxidase inhibitors, which are in use today [50]. However, despite the fact that these drugs are still in use and they demonstrate positive clinical effects, some studies indicate they are not always successful [51]: other studies report poor tolerance of their adverse effects, and quite long and low remission rate $[52,53]$. Further investigations are clearly needed to obtain more repeatable results and reliable therapies. With this in mind, as well as the potential of NMDA antagonists in treating psychiatric diseases such as schizophrenic depressive symptoms, memantine could represent a possible candidate for testing.

Some studies indicate that ketamine could be a promising agent in treating symptoms of major depressive disorder; however, this drug is not suitable for longer usage because of its addiction potential and strong psychomimetic character. No such properties have been observed for memantine; in addition, unlike the others, it can be administered orally [54].

Various clinical studies have examined the effects of NMDA antagonists. In one patient with very severe depressive symptoms, an infusion of ketamine was found to be helpful. His condition was initially poor: he had attempted suicide 10 times over the course of the previous 2 months and was resistant to various pharmacotherapy. Following treatment, the depressive symptoms were found to have been alleviated, as indicated by the Beck Depression Inventory (BDI) and 17item Hamilton Depression Rating Scale (HDRS); however, the effect was transient and the symptoms returned after a short time. As multiple infusion was not recommended due to the addictive properties of ketamine, the regimen was supplemented with memantine. BDI and HDRS testing found that the symptoms had receded and the patient was discharged after 13 weeks [55]. These findings confirm available scientific data where memantine has been proven to be a good adjunctive antidepressant therapy [56]. Memantine has also been found to shorten the lag time between antidepressant administration and clinical effects, and to improve early therapy response [57]. The relationship between depression and the NMDA tract is further reinforced by the fact that people with MDD (major depressive disorder) also demonstrate higher glutamate levels in the brain and blood. Memantine has also been found to be effective in treating depression comorbid with alcohol abuse; however, escitalopram (SSRI) was much more effective [58]. Frequent alcohol consumption blocks NMDA receptors, thus increasing the regulation of these receptors, and contributing to alcohol tolerance [59].

The complexity of the role played by NMDA receptors in mood disorders confirming clinical studies implementing glutamate neurotransmission in mood disorders results in a wide range of potential areas of study [59]. Memantine also positively affects BDNF (brainderived neurotrophic factor) production suggesting that glutamate plays an important role in the pathology and etiology of MDD [60-62]. It has also demonstrated synergistic effects when administered with different drugs: a 5-mg dose had an effect in Porsolt's preclinical test. When it was administered alongside with sertraline, the effect was visible at any given dose. Biochemical tests of BDNF levels also showed the same tendency [62]. In the case of drug resistance, the dose was increased from the standard 20 to $40 \mathrm{mg}$ with effective results; 
however, study group was quite low [63]. Elderly patients with dementia also demonstrated significant improvement in depressive symptoms when memantine was added to escitalopram treatment $[64,65]$. In addition, the addition of memantine to imipramine in preclinical forced swimming test showed promising results at all doses [66]. In contrast, a meta-analysis of trials found memantine to not significantly reduce depressive symptoms in any case [67]. Such variation may be attributed to variations in the makeup of the population or trial exclusion criteria or to various physical issues, taking different drugs, or the reason of their depression [68].

The treatment of depression is complicated by its wide variety of etiologies. Depressive disorders may be triggered by chronic inflammation in brain associated with chronically increased levels of cytokines or other inflammatory mediators [69]. Such elevation induces a chain of endocrine reactions leading to neurotoxicity [70]. As neuroplasticity plays a significant role in the onset of depression, less neuroplasticity is associated with greater visibility of symptoms [71]. One approved SSRI, fluoxetine, increases neural plasticity and improves the dysfunctional glutamatergic neurotransmission visible in patients with MDD [72, 73].

A range of clinical trials is underway to clarify the potential of NMDA antagonists such as memantine in treating depression. Despite the fact that ketamine is known to alleviate depressive symptoms, it is not completely clear whether the glutamate tract plays the only role. More reliable data can be obtained with the use of larger studies employing validated exclusion criteria or more homogenous patients. [74, 75]

\section{Summary}

Memantine is effective in treating some nervous system disorders and appears to be well tolerated by patients. The combination of memantine and various atypical antipsychotics also appears to offer great potential. Memantine also helps alleviate symptoms of dementia and significantly slows neurodegenerative processes. However, as psychiatric cases are so heterogeneous and require the individual treatment of almost every patient, further clinical studies are still needed. Nevertheless, the results of ongoing trials are very promising, with the majority yielding positive outcomes.

Funding Financial support by grant 2015/19/B/NZ7/02847 from the National Science Centre, Poland, is gratefully acknowledged.

\section{Compliance with ethical standards}

Conflict of interest The authors declare that they have no conflict of interest.
Open Access This article is licensed under a Creative Commons Attribution 4.0 International License, which permits use, sharing, adaptation, distribution and reproduction in any medium or format, as long as you give appropriate credit to the original author(s) and the source, provide a link to the Creative Commons licence, and indicate if changes were made. The images or other third party material in this article are included in the article's Creative Commons licence, unless indicated otherwise in a credit line to the material. If material is not included in the article's Creative Commons licence and your intended use is not permitted by statutory regulation or exceeds the permitted use, you will need to obtain permission directly from the copyright holder. To view a copy of this licence, visit http://creativecommons.org/licenses/by/4.0/.

\section{References}

1. Mayeux R, Sano M (2003) Treatment of Alzheimer's disease. N Engl J Med 341(22):1670-1679

2. M Prince, E Albanese, M Guerchet, M Prina (2014) World Alzheimer report 2014, dementia and risk reduction and analysis or protective and modifiable factors, Chap. 1, p. 6-10, https://www. alz.co.uk/research/world-report-2014. Accessed 1 Jun 2020

3. Lane CA, Hardy J, Schott JM (2018) Alzheimer's disease. Eur J Neurol 25:59-70

4. Wu Y-T, Fratiglioni L, Matthews FE, Lobo A, Breteler MMB, Skoog I, Brayne C (2015) Dementia in western Europe: epidemiological evidence and implications for policy making. Lancet Neurol S1474-4422(15):00092-00097

5. Andrade C (2017) Memantine as an augmentation treatment for schizophrenia, limitations of meta- analysis for evidence based evaluation of research. J Clin Psychiatry 78:9

6. M. Prince, A. Wimo, M. Guerchet, G.C. Ali, Y.T. Wu, M. Prina (2015) World Alzheimer report 2015, the global impact of dementia, an analysis of prevalence, incidence costs and trends, Chap. 2, p. 10-25, www.alz.co.uk/worldreport2015corrections. Accessed 1 Jun 2020

7. Matthews FE, Stephan BCM, Robinson L, Jagger C, Barnes LE, Arthur A, Brayne C A two decade dementia incidence comparison from the Cognitive Function and Ageing Studies I and II. Nat Commun 7:11398

8. Brayne C, Davis D (2012) Making Alzheimer's and dementia research fi t for populations. Lancet 380:1441-1443

9. Whalley LJ, Dick FD, McNeill G (2006) A life-course approach to the aetiology of late-onset dementias. Lancet Neurol 5:87-96

10. Larson EB, Yaffe K, Langa KM (2013) New insights into the dementia epidemic. N Engl J Med 369:24

11. Hardy J, Selkoe DJ The amyloid hypothesis of Alzheimer's disease: progress and problems on the road to therapeutics. Science 297(5580):353-356

12. Stelzma RA, Schnitzlein HN, Muriagh FR (1995) An English translation of Alzheimer's 1907 paper, "Uber eine eigenartige Erlranliung der Hirnrinde". Clin Anat 8:429-43 1 https:// onlinelibrary.wiley.com/doi/pdf/10.1002/ca.980080612

13. Weggen S, Beher D (2012) Molecular consequences of amyloid precursor protein and presenilin mutations causing autosomaldominant Alzheimer's disease. Alzheimers Res Ther 4:9

14. Liu C, Kanekiyo T, Xu H, Bu G (2013) Apolipoprotein E and Alzheimer disease: risk, mechanisms, and therapy. Nat Rev Neurol 9(2):106-118

15. Verghese PB, Castellano JM, Holtzman DM (2011) Apolipoprotein $\mathrm{E}$ in Alzheimer's disease and other neurological disorders. Lancet Neurol 10:241-252 
16. Karch CM, Goate AM (2015) Alzheimer's disease risk genes and mechanisms of disease pathogenesis. Biol Psychiatry 77:43-51

17. Witt A, Macdonald N, Kirkpatrick P (2004) Memantine hydrochloride. Nat Rev Drug Discov 3(2):109-110

18. Parsons CG, Danysz W, Quack G (1999) Memantine is a clinically well tolerated N-methyl-D-aspartate (NMDA) receptor antagonist $-\mathrm{a}$ review of preclinical data. Neuropharmacology 38 : 735-767

19. Gerzon K, Krumkalns EV, Brindle RL, Marshall FJ, Root MA (1963) The adamantyl group in medicinal agents. I. Hypoglycemic N-arylsulfonyl-N'-adamantylureas. J Med Chem 6: 760-763

20. Kemp JA, McKernan RM (2002) NMDA receptor pathway as drug target. Nat Neurosci 5 Suppl:1039-1042

21. Lorio GD, Baroni G, Lorusso M, Montemitro C, Chiara Spano M, Giannantonio MD (2017) Efficacy of memantine in schizophrenic patients: a systematic review. J Amino Acids 2017:70210717021076

22. Vetulani J (2004) Memantine - hope for treatment of dementia and other neurodegenerative disorders. Psychogeriatr Pol 1:39-50 https://docplayer.pl/6365034-Jerzy-vetulani-psychogeriatr-pol2004-1-39-50-streszczenie-praca-pogl1 dowa-review-paper-pgp-6issn-1732-2642.html. Accessed 1 Jun 2020

23. Kantrowitz JT, Javitt DC (2010) N-methyl-d-aspartate (NMDA) receptor dysfunction or dysregulation: the final common pathway on the road to schizophrenia? Brain Res Bull 83:108-121

24. Stone JM, Morrison PD (2007) Glutamate and dopamine dysregulation in schizophrenia - a synthesis and selective review. J Psychopharmacol 21:440-452

25. Irmak MK (2014) Schizophrenia or possesion? J Relig Health 53(3):773-777

26. Paraschakis A (2014) Tackling negative symptoms of schizophrenia with memantine. Case Rep Psychiatry 2014:384783-384783

27. Coyle JT $(2006,2006)$ Glutamate and schizophrenia: beyond the dopamine hypothesis. Cell Mol Neurobiol 26(4-6). https://doi.org/ 10.1007/s10571-006-9062-8

28. Owen MJ, Sawa A, Mortensen PB (2016) Schizophrenia. Lancet. 388(10039):86-97

29. Rezaei F, Mohammad-Karimi M, Seddighi S, Modabbernia A, Ashrafi M, Salehi B, Hammidi S, Motasami H, Hajiaghaee R, Tabrizi M, Akhondzadeh S (2013 Jun) Memantine add-on to risperidone for treatment of negative symptoms in patients with stable schizophrenia randomized, double-blind, placebo-controlled study. J Clin Psychopharmacol 33(3):336-342

30. Omranifard V, Rajabi F, Mohammadian-Sichani M, Maracy MR (2017) The effect of add-on memantine on positive, negative and depressive symptoms of schizophrenia: a doubleblind, randomized, controlled trial. Actas Esp Psiquiatr 45(3):108-115

31. John JP, Lukose A, Manjunath S (2014) Off -label use of memantine as adjunctive treatment in schizophrenia: a retrospective case series study. Pharmacopsychiatry 47:202-209

32. Fakhri A, Pakseresht S, Reza Haghdoost M, Hekmatkhah N, Torkashv M, Ghorbanzadeh B (2016) Memantine enhances the effect of olanzapine in patients with schizophrenia: a randomized, placebo-controlled study. Acta Medica Iranica 54(11):696-703

33. Stahl S (2008) "Antipsychotic agents." In Stahl's essential psychophar- macology, pp. 440-446, Cambridge University Press, 3rd edi- tion

34. Rammesa G, Rupprechta R, Ferraria U, Zieglgaènsbergera W, Parsons CG (2001) The N-methyl-d-aspartate receptor channel blockers memantine, (2001) MRZ 2/579 and other amino-alkylcyclohexanes antagonise 5-HT3 receptor currents in cultured HEK-293 and N1E-115 cell systems in a non-competitive manner. Neurosci Lett 306(1-2):81-84
35. Carpenter SS, Hatchett AD, Fuller MA (2006) Catatonic schizophrenia and the use of memantine. (2005). Ann Pharmacother 40(2):344-346

36. Lieberman JA, Papadakis K, Csernansky J, Litman R, Volavka J, Jia XD, Gage A (2008) A randomized, placebo-controlled study of memantine as adjunctive treatment in patients with schizophrenia. Neuropsychopharmacology 34(5):1322-1329

37. Kishi T, Matsuda Y, Iwata N (2017) Memantine add-on to antipsychotic treatment for residual negative and cognitive symptoms of schizophrenia: a meta-analysis. Psychopharmacology 234(14): 2113-2125

38. Kendler KS (2016) The phenomenology of major depression and the representativeness and nature of DSM criteria. Am J Psychiatry 173(8):771-780

39. Trede K, Salvatore P, Baethge C, Gerhard A, Maggini C, Baldessarini RJ (2005) Manic-depressive illness: evolution in Kraepelin's textbook, 1883-1926. Harvard Rev Psychiatry 13(3): $155-178$

40. Lewis AJ (1934) Melancholia: a clinical survey of depressive states. J Ment Sci 80(329):277-378

41. Kendler KS, Karkowski LM, Prescott CA (1999) Causal relationship between stressful life events and the onset of major depression. Am J Psychiatry 156(6):837-841

42. Caspi A, Sugden K, Moffitt TE, Taylor A, Craig IW, Harrington H, McClay J, Mill J, Martin J, Braithwaite A, Poulton R (2003) Polymorphism in the 5-HTT gene influence of life stress on depression: moderation by a polymorphism in the 5-HTT gene. Science 301-386(2003):386-389

43. Malhi GS, Bassett D, Boyce P, Bryant R, Fitzgerald PB, Fritz K, Hopwood M, Lyndon B, Mulder R, Murray G, Porter R, Singh AB (2015) Royal Australian and New Zealand College of Psychiatrists clinical practice guidelines for mood disorders. Aust N Z J Psychiatry 49(12):1087-1206

44. Baune BT, Boyce P, Morris G, Hamilton A, Bassett D, Hopwood M, Mulder R, Parker G, Porter R, Singh AB, Outhred T, Das P, Malhi GS (2019) Organising the front line: is there a rationale for the first-line pharmacotherapy of major depressive disorder? Aust N Z J Psychiatry 53(4):279-281

45. Paolucci $S$ (2017) Advances in antidepressants for treating poststroke depression. Expert Opin Pharmacother 18(10):1011-1017

46. Psychogiou L, Russell G, Owens M (2019) Parents' postnatal depressive symptoms and their children's academic attainment at 16 years: pathways of risk transmission. Br J Psychol 111:1-16

47. Asuquo JE, Edet BE, Abang IE, Essien EA, Osakwe OG, Aigbomain EJ, Chigbundu KC (2017) Depression and posttraumatic stress disorder among road traffic accident victims managed in a tertiary hospital in Southern Nigeria. Niger J Clin Pract 20(2): $170-175$

48. Coppen A (1967) The biochemistry of Affectie disorders. Brit J Psychiat 113:1237-1264

49. Schildkraut JJ (1965) The catecholamine hypothesis of affective disorders: a review of supporting evidence. Am J Psychiatry 122(5):509-522

50. Doboszewska U, Wlaź P, Nowak G, Radziwoń-Zaleska M, Cui R, Młyniec K (2017) Zinc in the monoaminergic theory of depression: its relationship to neural plasticity. Neural Plast 2017:3682752

51. Trivedi MH, Rush AJ, Wisniewski SR, Nierenberg AA, Warden D, Ritz L, Norquist G, Howland RH, Lebowitz B, McGrath PJ, Shores-Wilson K, Biggs MM, Balasubramani GK, Fava M (2006) Evaluation of outcomes with citalopram for depression using measurement-based care in $\mathrm{STAR}^{*} \mathrm{D}$ : implications for clinical practice. Am J Psychiatry 163(1):28-40

52. Folch J, Busquets O, Ettcheto M, Sánchez-López E, Castro-Torres RD, Verdaguer E, Garcia ML, Olloquequi J, Casadesús G, BeasZarate C, Pelegri C, Vilaplana J, Auladell C, Camins A (2018) 
Memantine for the treatment of dementia: a review on its current and future applications. J Alzheimers Dis 62(3):1223-1240

53. Krishnan V, Nestler EJ (2008, Nature) The molecular neurobiology of depression. 455(7215):894-902

54. Zarate CA Jr, Singh JB, Carlson PJ, Brutsche NE, Ameli R, Luckenbaugh DA, Charney DS, Manji HK (2006) A randomized trial of an N-methyl-D-aspartate antagonist in treatment-resistant major depression. Arch Gen Psychiatry 63(8):856-864

55. Kollmar R, Markovic K, Thürauf N, Schmitt H, Kornhuber J (2008) Ketamine followed by memantine for the treatment of major depression. Aust N Z J Psychiatry 42(2):170

56. Smith EG, Deligiannidis KM, Ulbricht CM, Landolin CS, Patel JK, Rothschild AJ (2013) Antidepressant augmentation using the Nmethyl-D-aspartate antagonist memantine: a randomized, doubleblind, placebo-controlled trial. J Clin Psychiatry 74(10):966-973

57. Amidfar M, Khiabany M, Kohi A, Salardini E, Arbabi M, Roohi Azizi M, Zarrindast MR, Mohammadinejad P, Zeinoddini A, Akhondzadeh S (2017) Effect of memantine combination therapy on symptoms in patients with moderate-to-severe depressive disorder: randomized, double-blind, placebo-controlled study. J Clin Pharm Ther 42(1):44-50

58. Muhonen LH, Lönnqvist J, Juva K, Alho H (2008) Double-blind, randomized comparison of memantine and escitalopram for the treatment of major depressive disorder comorbid with alcohol dependence. J Clin Psychiatry 69(3):392-399

59. Krystal JH, Petrakis IL, Limoncelli D, Webb E, Gueorgueva R, D'Souza DC, Boutros NN, Trevisan L, Charney DS (2003) Altered NMDA glutamate receptor antagonist response in recovering ethanol-dependent patients. Neuropsychopharmacology 28(11):2020-2028

60. Krystal J, Petrakis I, Limoncelli D et al (2003) Altered NMDA glutamate receptor antagonist response in recovering ethanoldependent patients. Neuropsychopharmacol 28:2020-2028

61. Rogóz Z, Skuza G, Legutko B Repeated co-treatment with imipramine and amantadine induces hippocampal brain-derived neurotrophic factor gene expression in rats. J Physiol Pharmacol 58(2): 219-234

62. Amidfar M, Réus GZ, Quevedo J, Kim Y-K, Arbabi M (2017) Effect of co-administration of memantine and sertraline on the antidepressant-like activity and brain-derived neurotrophic factor (BDNF) levels in the rat brain. Brain Res Bull. https://doi.org/10. 1016/j.brainresbull.2016.11.003

63. Ferguson JM, Shingleton RN (2007) An open-label, flexible-dose study of memantine in major depressive disorder. Clin Neuropharmacol 30(3):136-144
64. Pelton GH, Harper OL, Roose SP, Marder K, D'Antonio K, Devanand DP (2016) Combined treatment with memantine/escitalopram for older depressed patients with cognitive impairment: a pilot study. Int J Geriatr Psychiatry 31(6):648-655

65. Ford AH, Almeida OP (2017) Management of depression in patients with dementia: is pharmacological treatment justified? Drugs Aging 34(2):89-95

66. Réus GZ, Stringari RB, Kirsch TR, Fries GR, Kapczinski F, Roesler R, Quevedo J (2010) Neurochemical and behavioural effects of acute and chronic memantine administration in rats: further support for NMDA as a new pharmacological target for the treatment of depression? Brain Res Bull 81(6):585-589

67. Kishi T, Matsunaga S, Iwata N (2017) A meta-analysis of memantine for depression. J Alzheimers Dis 57(1):113-121

68. Amidfar M, Réus GZ, Quevedo J, Kim YK (2018) The role of memantine in the treatment of major depressive disorder: clinical efficacy and mechanisms of action. Eur J Pharmacol 827:103-111

69. Jeon SW, Kim Y-K (2017) Inflammation-induced depression: its pathophysiology and therapeutic implications. J Neur Immun. https://doi.org/10.1016/j.jneuroim.2017.10.016

70. Vasileva LV, Ivanovska MV, Murdjeva MA, Saracheva KE, Georgiev MI $(2019,2019)$ Immunoregulatory natural compounds in stress-induced depression: an alternative or an adjunct to conventional antidepressant therapy? Food Chem Toxicol. https://doi. org/10.1016/j.fct.2019.03.004

71. Duman RS, Aghajanian GK, Sanacora G, Krystal JH (2016) Synaptic plasticity and depression: new insights from stress and rapid-acting antidepressants. Nat Med 22(3):238-249

72. Ampuero E, Rubio FJ, Falcon R, Sandoval M, Diaz-Veliz G, Gonzalez RE, Earle N, Dagnino-Subiabre A, Aboitiz F, Orrego F, Wyneken U (2010) Chronic fluoxetine treatment induces structural plasticity and selective changes in glutamate receptor subunits in the rat cerebral cortex. Neuroscience 169(1):98-108

73. Valentine GW, Sanacora G (2009) Targeting glial physiology and glutamate cycling in the treatment of depression. Biochem Pharmacol 78(5):431-439

74. Dennis S et al (2003) Depression and Bipolar Support alliance Consensus statement on the unmet needs in diagnosis and treatment of mood disorders in late life. Arch Gen Psychiatry 60:664-672

75. Hashimoto K (2009) Emerging role of glutamate in the pathophysiology of major depressive disorder. Brain Res Rev 61(2):105-123

Publisher's note Springer Nature remains neutral with regard to jurisdictional claims in published maps and institutional affiliations. 